\title{
Environmental risk assessment and field performance of rose (Rosa Xhybrida) genetically modified for delphinidin production
}

\author{
Noriko Nakamura, ${ }^{1, *}$, Masako Fukuchi-Mizutani ${ }^{1}$, Yukihisa Katsumoto ${ }^{1}$, \\ Junichi Togami ${ }^{1}$, Mick Senior ${ }^{2}$, Yoshie Matsuda ${ }^{3}$, Keiji Furuichi ${ }^{3}$, Mie Yoshimoto $^{3}$, \\ Akihiro Matsunaga ${ }^{3}$, Kanako Ishiguro ${ }^{1}$, Mitsuhiro Aida ${ }^{4}$, Masao Tasaka ${ }^{4}$, \\ Hirokazu Fukui ${ }^{5}$, Shinzo Tsuda ${ }^{1}$, Steve Chandler ${ }^{2}$, Yoshikazu Tanaka ${ }^{1}$ \\ ${ }^{1}$ Institute for Plant Science, Suntory Holdings Ltd., Mishima, Osaka 618-8503, Japan; ${ }^{2}$ Florigene Pty Ltd., Bundoora, \\ Victoria, 3083, Australia; ${ }^{3}$ NISSHOKU Co., Tsuyama, Okayama, 708-8652, Japan; ${ }^{4}$ Faculty of Bioscience, Nara \\ Institute of Advanced Science and Technology, Takayama, Nara, 630-0192, Japan; ${ }^{5}$ Faculty of Agriculture, Gifu \\ University, Gifu, 501-1112, Japan \\ *E-mail: Noriko_Nakamura@suntory.co.jp Tel: +81-75-962-8807 Fax: +81-75-962-3791
}

Received November 12, 2010; accepted January 13, 2011 (Edited by M. Ono)

\begin{abstract}
The release of genetically modified plants into the environment can only occur after permission is obtained from the relevant regulatory authorities. This permission will only be obtained after extensive risk assessment shows comparable risk of impact to the environment and biodiversity as compared to non-transgenic host plants. Two transgenic rose (Rosa $\times$ hybrida) lines, whose flowers were modified to a bluer colour as a result of accumulation of delphinidin-based anthocyanins, have been trialed in greenhouses and the field in both Japan and Australia. Flower colour modification was due to expression of genes of a viola flavonoid 3',5'-hydroxylase and a torenia anthocyanin 5-acyltransferase. In all trials it was shown that the performance of the two transgenic lines, as measured by their growth characters, was comparable to the host untransformed variety. Biological assay showed that the transgenic lines did not produce allelopathic compounds. In Japan, seeds from wild rose species that had grown in close proximity to the transgenic roses did not carry either a Rosa $\times$ hybrida specific marker gene or the transgenes. In hybridization experiments using transgenic rose pollen and wild rose female parents, the transgenes were not detected in the seed obtained, though there was a low frequency of seed set. The transgene was also not transmitted when Rosa $\times$ hybrida cultivars were used as females. In in situ hybridization analysis transgene transcripts were only detected in the epidermal cells in the petals of the transgenic roses. In combination, the breeding and in situ analysis results show that the transgenic roses contain the transgene only in the L1 layer cells and not in the L2 layer cells that generate reproductive cells. General release permissions have been granted for both transgenic lines in Japan and one is now commercially produced.
\end{abstract}

Key words: Environmental risk assessment, gene flow, genetically modified organism (GMO), periclinal chimera, transgenic rose.

Cultivated rose $($ Rosa $\times$ hybrida $)$ is the most beloved of flowers and economically the most important cut flower in the world. Roses are a number of complex interspecific hybrids derived from breeding with a handful of wild species (Gudin 2000). In spite of such extensive breeding, roses do not synthesize delphinidin-based anthocyanins contained in most blue or violet flowers, due to the absence of flavonoid 3', 5'-hydroxylase $\left(\mathrm{F}^{\prime} 5^{\prime} \mathrm{H}\right)$, a key enzyme for delphinidin biosynthesis. Genetically modified (GM) roses with flowers having a blue hue were recently generated (Katsumoto et al. 2007) as a result of expression of a viola gene for $F 3^{\prime} 5^{\prime} H$.
The requirements for the risk assessment of GM crops are documented in the templates of Article 15 and Annex II of the Cartagena Protocol on Biosafety (Shinoyama et al. 2008) though the procedure of the legal assessment and permission process depends on country and to some extent the area within a country (Tanaka et al. 2009). In Japan, GM plants are assessed on three major criteria: 1 . Substantial equivalence of the relevant GM plant in comparison to the host, by comparing factors such as growth characters and reproducibility, 2. Unique production of potentially harmful substances by the GM plant, 3. Possibility of hybridization of the GM plant

Abbreviations: 5AT, anthocyanin 5-acyltransferase; ANS, anthocyanidin synthase; F3'5' H, flavonoid 3',5'-hydroxylase; GM, genetically modified; GMO, genetically modified organism; TFL1, TERMINAL FLOWER1; GAPDH, glyceraldehyde 3-phosphate dehydrogenase; nptII, neomycin phosphotransferase II; ETR1, ethylene response 1

This article can be found at http://www.jspcmb.jp/ 


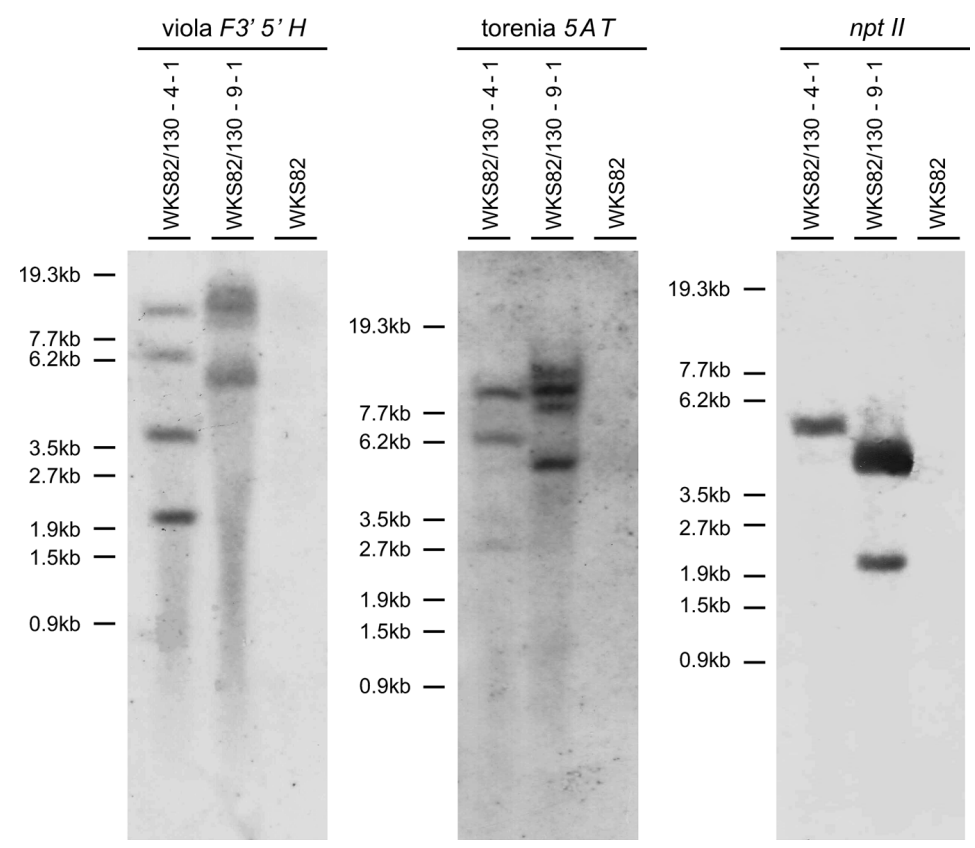

Figure 1. Southern analysis of GM rose. $20 \mu \mathrm{g}$ of genomic DNA was digested with NcoI, ClaI or PstI and then subjected to analysis using the viola $F 3^{\prime} 5^{\prime} \mathrm{H}$ gene, the torenia $5 A T$ gene and the $n p t I I$ gene to estimate the number of loci integrated.

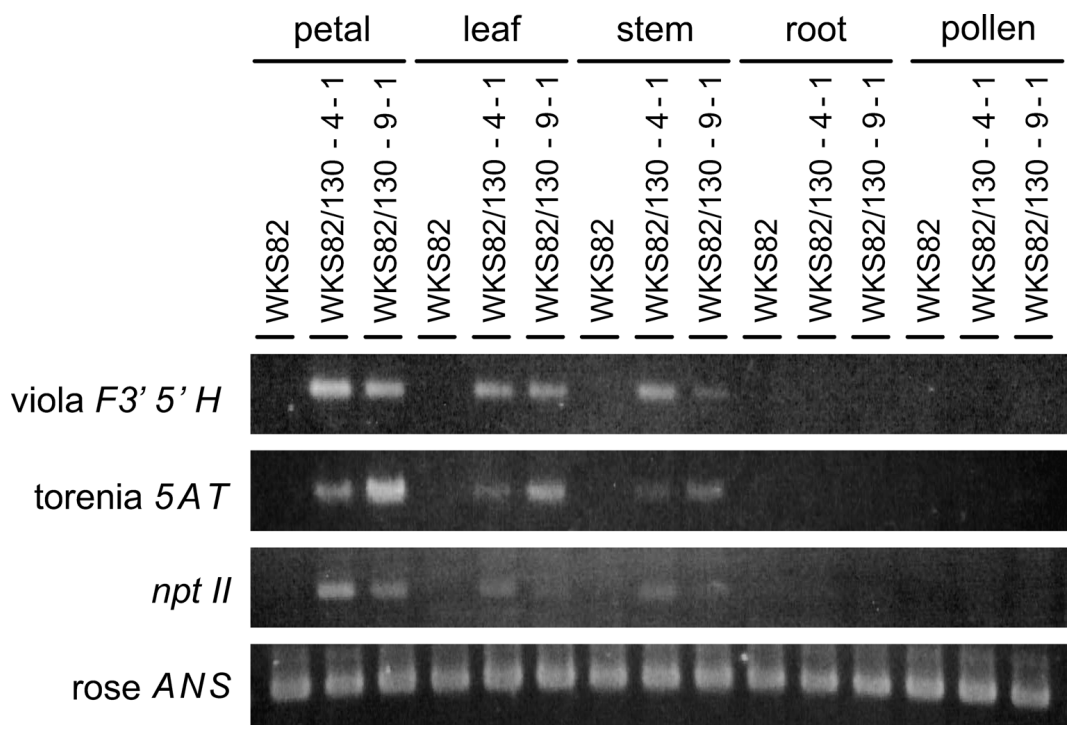

Figure 2. PCR analysis of various organs in the host and the two GM roses. PCR analysis to detect the transgenes (viola $F 3^{\prime} 5^{\prime} H$ gene, the torenia $5 A T$ gene, the $n p t I I$ gene and the rose $A N S$ gene) in various organs of GM rose.

with native species.

There are two steps in the permission process to obtain a general release in Japan. Firstly, a small scale field trial is carried out in a contained environment and information on compatibility and the biology of the host species is gathered. An application for general release permission is then applied for on the basis of the field trial data gathered. Although over one hundred different GMOs have been granted general release permission in Japan (http://www.bch.biodic.go.jp). Prior to the rose, only violet GM carnations expressing $F 3^{\prime} 5^{\prime} H$ and dihydroflavonol 4-reductase (DFR) genes (Tanaka et al.
2009) have been available to Japanese flower consumers. The transgenic carnations are produced overseas, and no GMO was produced in a field under the current legal system in Japan until 2008, when one of the two GM rose lines described here was commercially grown. Insect resistance GM chrysanthemum expressing a Bacillus thuringiensis insecticidal gene has been assessed, and the assessment protocol and results have been reported in details (Shinoyama et al. 2008).

Modern varieties of Rosa $\times$ hybrida are tetraploid while most Japanese wild roses are diploids. In a separate study, we extensively analyzed the seedlings of Japanese 
wild roses ( $R$. multiflora, $R$. luciae and $R$. rugosa) growing in close proximity to Rosa $\times$ hybrida and detected no gene flower from Rosa $\times$ hybrida to the wild roses in the wild (Nakamura et al. 2011). In that study, the $K S N$ gene (a perpetual flowering gene found in cultivated rose but not Japanese wild roses) was used as a marker to detect whether there was any gene flow. The results indicate that such gene flow did not occur and that release of GM rose would not lead to introgression with Japanese wild roses. However, since some populations of $R$. acicularis are tetraploid, the possibility of their hybridization to Rosa $\times$ hybrida was assessed by manual

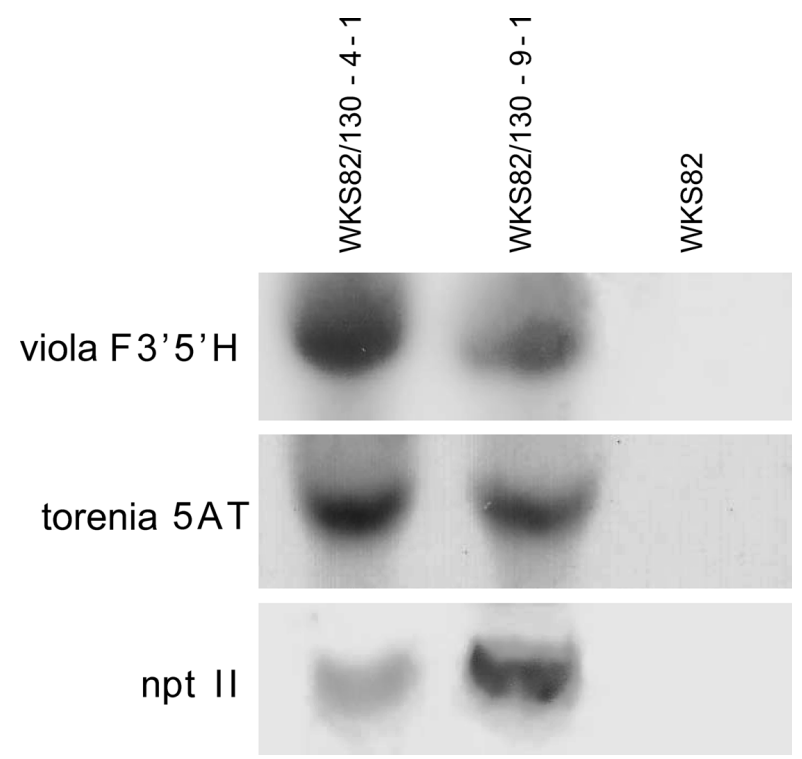

Figure 3. Northern analysis of GM rose. $20 \mu \mathrm{g}$ of total RNA was subjected to analysis to detect transcripts of the viola $F 3^{\prime} 5^{\prime} H$ gene, the torenia $5 A T$ gene and the nptII gene. hybridization, and the results of that study are reported here.

We have assessed the two transgenic rose lines expressing the viola $F 3^{\prime} 5^{\prime} H$ and torenia $5 A T$ genes, collected comprehensive data relevant to their possible impacts on biodiversity in Japan. The results of greenhouse trial at a rose grower in Australia are also presented in this study. The results indicate that the release of the two transgenic rose lines is most unlikely to affect Japanese biodiversity. Consequentially, general release permissions was granted for the transgenic rose.

\section{Materials and methods \\ Plant material and cultivation}

The host rose variety used in this study was WKS82 (Keisei Rose Nurseries Inc., Registration of variety application No.: 17636). The two transgenic rose lines WKS82/130-4-1 and WKS82/130-9-1 (the two GM rose lines) were selected on the basis of flower colour and flower colour stability from 44 lines of WKS82 transformed using binary vector pSPB130 as described by Katsumoto et al. (2007). pSPB130 contains a viola $F 3^{\prime} 5^{\prime} H$ gene and a torenia $5 A T$ gene to modify anthocyanin structure and the $n p t I I$ gene as a selectable marker. In Japan, roses were grown in a contained or special-netted greenhouse in Suntory Research Center (Osaka, Japan) from February 2002 to April 2006. In these trials, growth parameters were measured from the plants, which were cultivated in rockwool. A field trial (Tsuyama, Japan) was carried out from May 2006 to January 2008. In these trials, the roses were grown in both a vinyl plastic covered house and outside.

Tissue culture plants of the host and the two GM rose lines were exported to Florigene Pty Ltd. (Victoria, Australia) and plants were de-flasked in April 2004 and propagated in $9 \mathrm{~cm}$ pots. In March 2006 a license was issued by the Office of the
WKS82 Control

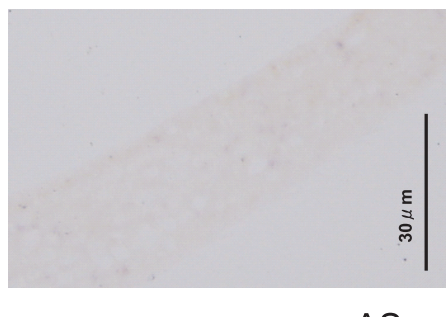

AS

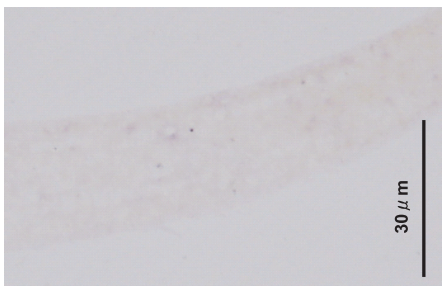

S
WKS82/130-4-1

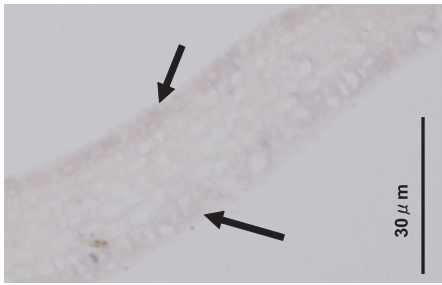

AS

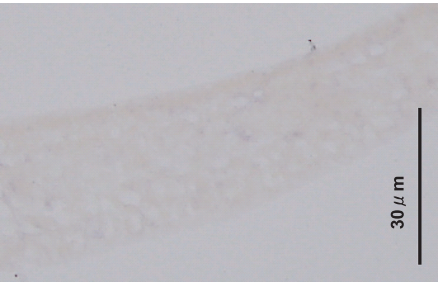

S
WKS82/130-9-1
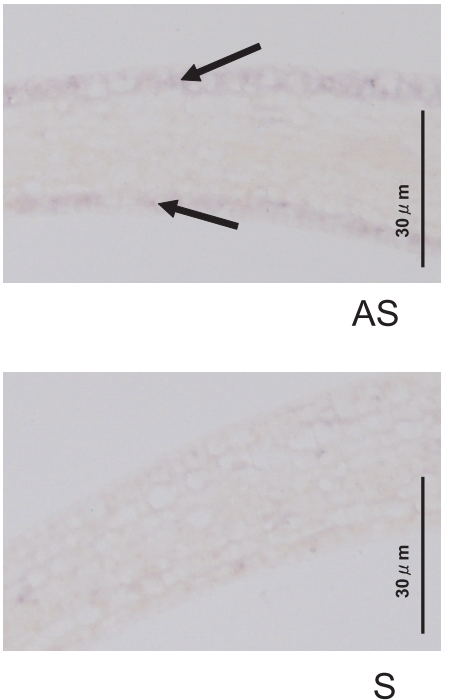

Figure 4. In situ hybridization analysis to identify petal cell layers transcribing the viola $F 3^{\prime} 5^{\prime} H$ gene. An antisense probe of the viola $F 3^{\prime} 5^{\prime} H$ gene (AS) was used for detection and a sense probe of the viola $F 3^{\prime} 5^{\prime} H$ gene (S) was for a control. Arrows indicate L1 layer. 
Table 1. Comparison of morphological parameters

\begin{tabular}{|c|c|c|c|}
\hline & WKS82 & WKS82/130-4-1 & WKS82/130-9-1 \\
\hline \multicolumn{4}{|l|}{ special netted greenhouse trial } \\
\hline flower size $(\mathrm{cm}, \mathrm{n}=10)$ & $9.2 \pm 0.8$ & $8.6 \pm 0.8$ & $8.6 \pm 1.2$ \\
\hline petal number $(n=10)$ & $33.2 \pm 7.1$ & $25.2 \pm 2.9^{*}$ & $28.1 \pm 2.2 *$ \\
\hline anther number $(\mathrm{n}=10)$ & $100.3 \pm 24.0$ & $116.3 \pm 7.6$ & $120.9 \pm 9.7^{*}$ \\
\hline anther length $(\mathrm{mm}, \mathrm{n}=20)$ & $3.8 \pm 0.2$ & $3.9 \pm 0.2$ & $3.8 \pm 0.2$ \\
\hline anther width $(\mathrm{mm}, \mathrm{n}=20)$ & $1.8 \pm 0.0$ & $1.9 \pm 0.1$ & $1.9 \pm 0.1$ \\
\hline \multicolumn{4}{|c|}{ field trial (vinyl plastic covered house) } \\
\hline flower size $(\mathrm{cm}, \mathrm{n}=20)$ & $7.6 \pm 1.3$ & $7.7 \pm 1.5$ & $7.9 \pm 1.5$ \\
\hline petal number $(n=20)$ & $32.6 \pm 6.8$ & $25.9 \pm 3.7 *$ & $26.5 \pm 3.9$ \\
\hline anther number $(n=20)$ & $104.0 \pm 20.8$ & $115.4 \pm 17.6$ & $114.9 \pm 14.0$ \\
\hline anther length $(\mathrm{mm}, \mathrm{n}=20)$ & $3.5 \pm 0.3$ & $3.4 \pm 0.4$ & $3.5 \pm 0.4$ \\
\hline anther width $(\mathrm{mm}, \mathrm{n}=20)$ & $1.4 \pm 0.3$ & $1.4 \pm 0.3$ & $1.4 \pm 0.3$ \\
\hline \multicolumn{4}{|l|}{ field trail (outside) } \\
\hline flower size $(\mathrm{cm}, \mathrm{n}=20)$ & $7.7 \pm 0.7$ & $7.6 \pm 0.8$ & $7.7 \pm 0.9$ \\
\hline petal number $(n=20)$ & $32.8 \pm 6.1$ & $23.9 \pm 3.9^{*}$ & $25.3 \pm 3.3 *$ \\
\hline anther number $(n=20)$ & $115.0 \pm 16.3$ & $115.7 \pm 11.6$ & $123.6 \pm 9.1$ \\
\hline anther length $(\mathrm{mm}, \mathrm{n}=20)$ & $3.6 \pm 0.4$ & $3.6 \pm 0.4$ & $3.8 \pm 2.2$ \\
\hline anther width $(\mathrm{mm}, \mathrm{n}=20)$ & $1.5 \pm 0.3$ & $1.4 \pm 0.3$ & $1.5 \pm 0.3$ \\
\hline \multicolumn{4}{|l|}{ trail in Australia } \\
\hline flower size $(\mathrm{cm}, \mathrm{n}=15)$ & $5.5 \pm 0.9$ & $5.7 \pm 0.9$ & $6.2 \pm 1.1$ \\
\hline petal number $(n=15)$ & $38 \pm 13$ & $28 \pm 7 *$ & $27 \pm 5^{*}$ \\
\hline anther number $(\mathrm{n}=50)$ & $110 \pm 23$ & $114 \pm 20$ & $136 \pm 18^{*}$ \\
\hline anther length $(\mathrm{mm}, \mathrm{n}=50)$ & $2.5 \pm 0.4$ & $2.7 \pm 0.1$ & $2.6 \pm 0.1$ \\
\hline
\end{tabular}

Data are expressed as the mean \pm standard deviation of these mesurements.

$* \mathrm{P}<0.05$ (Student's $t$ test)

Gene Technology Regulator (the Australia regulatory organization) to allow a greenhouse trial of the transgenic roses (License no DIR060/2005. Propagation and trial of imported rose lines, www.ogtr.gov.au). Plants were grown in a greenhouse of Australian Roses (Silvan, Victoria, Australia).

Rosa $\times$ hybrida (cv. Queen Elizabeth and cv. Gold Bunny), $R$. multiflora, R. luciae and R. rugosa were purchased from local rose nurseries or kindly provided by Dr. Takeuchi (Kesei Rose Nursery Inc). R. acicularis plants at three sites in Hokkaido (the Botanical Garden Hokkaido University (Sapporo, Japan), Hokkaido Forestry Research Institute (Bibai, Japan) and a private property (Sapporo)) were used for on site crossing experiments. $R$. acicularis plants obtained from Hokkaido Forestry Research Institute were vegetatively propagated in the vinyl plastic covered house. Lettuce (cv. Cisco) seeds were purchased from Takii Seed Co. Ltd. (Kyoto, Japan).

\section{Molecular analysis}

The procedures used for molecular and flavonoid analyses were as described in previous studies (Fukuchi-Mizutani et al. 2003). For Southern and PCR analysis, rose genomic DNA was prepared from various organs using Nucleon PHYTOPURE plant DNA extraction kit (GE Healthcare UK Ltd., Little Chalfont, UK) or DNeasy Plant Mini Kit (QIAGEN, Valencia, USA).

To reveal the presence of transgenes in various organs, the following primers were used as pairs in a PCR reaction using $100 \mathrm{ng}$ of genomic DNA as the template: BP40-F2 (5'-GAGC TAGGCCACATGCTTA-3') and BP40-R3 (5'-CTTTGCGCTCATGACTCG-3') for the viola $F 3^{\prime} 5^{\prime} H$ gene, TAT7-50F (5'AACAATATGTGCAGTCCTCGAA-3') and TAT7-R1 (5'-AA-
CTCGCATCGCCAACTAC- $3^{\prime}$ ) for torenia $5 A T$ gene and NPTII-F (5'-GATTGAACAAGATGGATTGCACGC-3') and NPTII-R (5'-CGAAGAACTCCAGCATGAGATCCC-3') for the nptII gene. For a positive control, a rose anthocyanidin symthase (ANS) DNA fragment was amplified with Rh ANS 69-r1 (5'-TTTGATCTTCCCATTGAGC-3') and Rh ANS 69m1 (5'-TCCGCGGTGGGAAGATCCCC-3'). Amplification was performed in a $50 \mu \mathrm{L}$ reaction containing $0.25 \mathrm{mM}$ dNTPs, $0.4 \mu \mathrm{M}$ each primer, $1 \mathrm{x}$ TaKaRa Ex Taq ${ }^{\mathrm{TM}}$ reaction buffer and $2.5 \mathrm{U}$ of Ex Taq ${ }^{\mathrm{TM}}$ DNA polymerase (Takara Bio Inc., Otsu, Japan). Reactions were initially denatured at $94^{\circ} \mathrm{C}$ for $5 \mathrm{~min}$, followed by 25 cycles of $94^{\circ} \mathrm{C}$ for $30 \mathrm{~s}, 55^{\circ} \mathrm{C}$ for $30 \mathrm{~s}$ and $72^{\circ} \mathrm{C}$ for $1 \mathrm{~min}$ for amplification.

For Northern and RT-PCR analysis, rose total RNA was extracted from various organs using RNeasy Plant Mini Kit (QIAGEN). cDNA used for the template of RT-PCR was synthesized with oligo-dT primers using the SuperScript ${ }^{\mathrm{TM}}$ First-Strand Synthesis System (Life Technologies, Carsbad, USA) following the manufacturer's protocol. The same sets of primers were used to amplify the transcripts of viola $F 3^{\prime} 5^{\prime} H$, torenia $5 A T$ and nptII. For a positive control, ETRl (ethylene response 1) transcripts (AF380127) were amplified using a pair of primers (ETR-F1 5'-TGTGGAGCGACACATCTTAT-3', ETR1-R1 5'-GCAGCATGTGAAAGAGCAAC-3'). The reaction conditions were the same as described above.

A strand specific RNA probe of viola $F 3^{\prime} 5^{\prime} H$ gene was generated using a plasmid pBluescript SKII $^{-}$(Agilent Technology Inc., Santa Clara, USA) containing a viola $F 3^{\prime} 5^{\prime} H$ cDNA and DIG RNA Labeling Kit (Roche Diagnostics, Mannheim, Germany) following the manufacturer's protocol. The probes used for in situ hybridization of the rose petal 


\section{A}

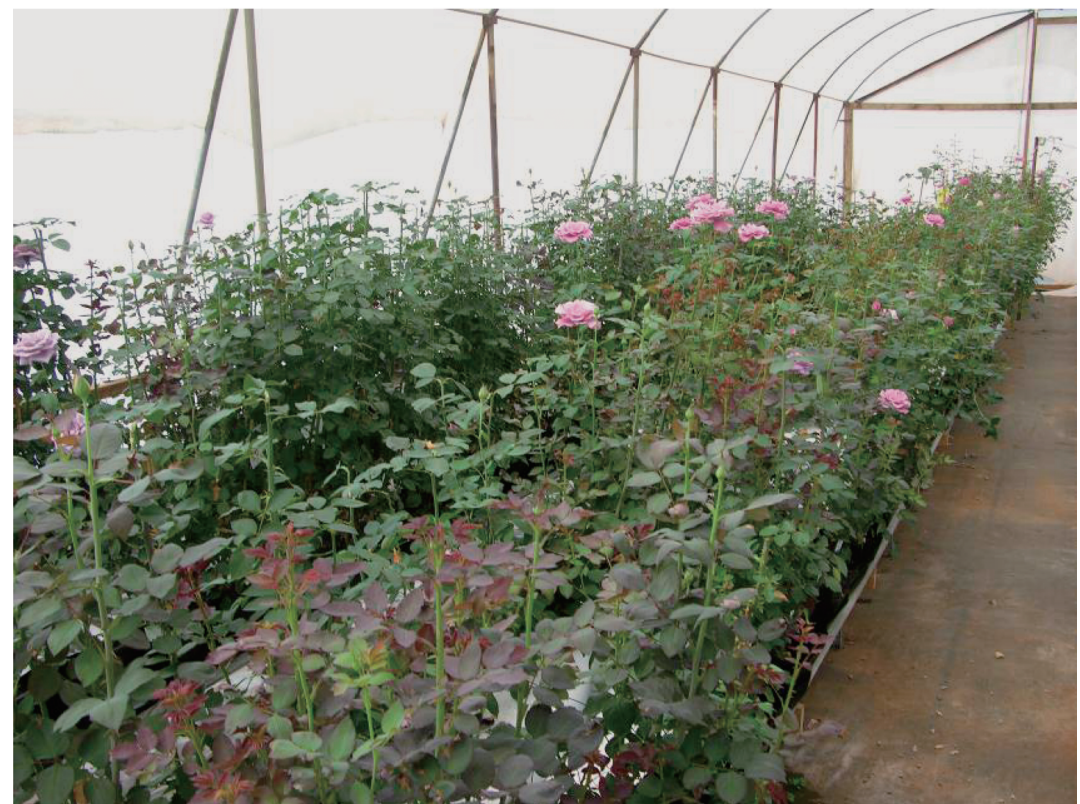

B

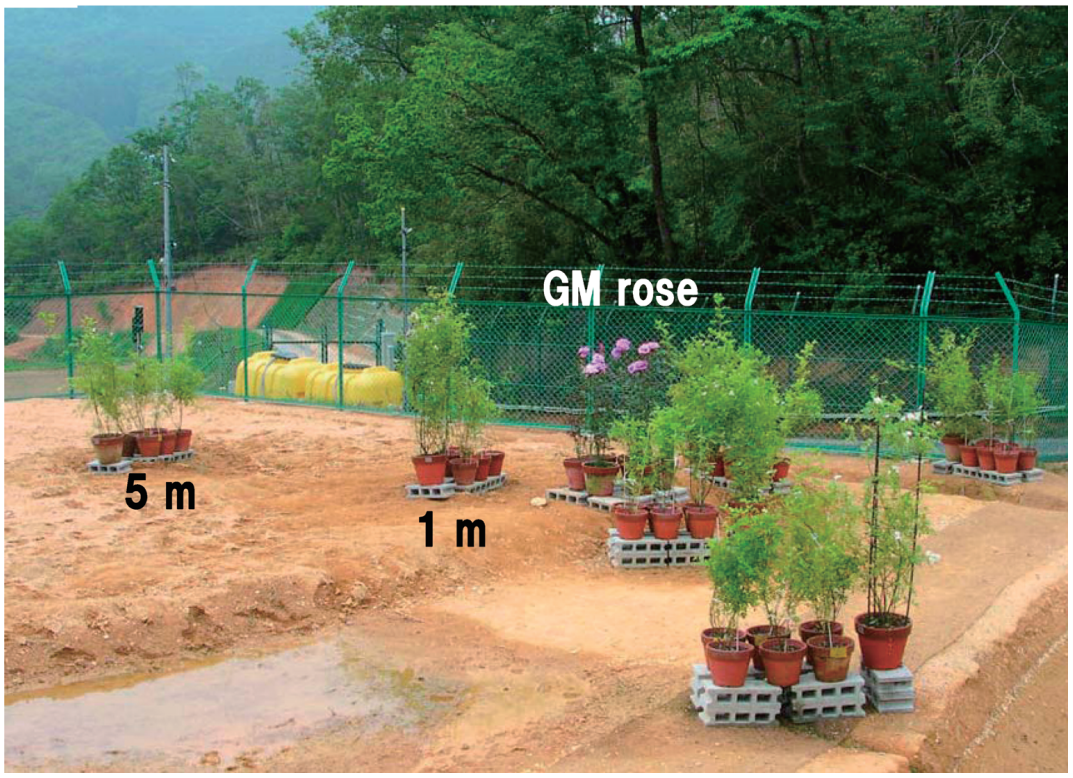

Figure 5. Field trial in Australia and Japan. A. The growth of the host and the GM rose in Australia trial. Comparative trial of the host and the two GM rose lines in Australia. B. Natural crossing in the field. $R$. multiflora plants were placed at distances of $1 \mathrm{~m}$ and $5 \mathrm{~m}$ from the flowering plants of one of GM rose lines.

sections were as previously described (Aida et al. 1999).

\section{Detection of gene transfer from Rosaxhybrida to wild rose species}

Genomic DNA was recovered from the embryo of wild rose seeds or young leaves of seedlings using the Nucleon PHYTOPURE plant DNA extraction kit. DNA was then amplified using the REPLI-g Midi Kit (QIAGEN) following the manufacturer's protocol. Amplified DNA was subjected to PCR to detect the KSN locus using a pair of primers (KSNIF3 (5'-CATATTATGGCATAGGGTGTGGC-3') and KSNInsR3 $\left(5^{\prime}\right.$-TGTAATCTGTAGGAGATCCCATGC-3')). For a positive control, a GAPDH DNA fragment was amplified (RhGAPDH$237 \mathrm{~F} \quad\left(5^{\prime}\right.$-TGTCATCTCTGCCCCAAGTAAGG- $\left.3^{\prime}\right)$ and RhGAPDH-724R (5'-CAACATCCTCATCGGTGTAACCC-3')) as described elsewhere (Nakamura et al. 2011).

\section{Measurement of morphological and growth characteristics}

Data presented in this study were mostly obtained in Japan unless otherwise noted. In Japan, the host and the GM rose plants were grown in 6 inch clay pots containing mixture soil (Akadama: BM-2: Kingpearl=4 : 2:1) from July 2004 to April 2006. In May 2005, plant height, number of nodes, flowering 
Table 2. Size and fertility of pollen

\begin{tabular}{lccc}
\hline & WKS82 & WKS82/130-4-1 & WKS82/130-9-1 \\
\hline \hline special netted greenhouse trial & & & \\
\hline mature pollen rate (\%) & $81.3 \pm 4.9$ & $83.3 \pm 3.8$ & $83.9 \pm 3.9$ \\
rate of pollen germination (\%) & $27.2 \pm 8.6$ & $31.0 \pm 8.3$ & $27.2 \pm 9.7$ \\
pollen size $(\mu \mathrm{m})$ & $47.3 \pm 2.0$ & $47.8 \pm 1.1$ & $48.2 \pm 0.7$ \\
\hline field trial (vinyl plastic covered house) & & & \\
\hline mature pollen rate (\%) & $79.2 \pm 1.3$ & $79.3 \pm 1.6$ & $79.4 \pm 1.9$ \\
rate of pollen germination (\%) & $25.9 \pm 1.5$ & $26.6 \pm 1.3$ & $25.3 \pm 1.1$ \\
pollen size $(\mu \mathrm{m})$ & $47.5 \pm 2.7$ & $47.7 \pm 3.0$ & $47.7 \pm 1.6$ \\
\hline field trail (outside) & & & \\
\hline mature pollen rate $(\%)$ & $79.7 \pm 2.5$ & $79.7 \pm 1.3$ & $79.9 \pm 1.1$ \\
rate of pollen germination $(\%)$ & $27.8 \pm 1.3$ & $27.0 \pm 1.5$ & $26.9 \pm 1.5$ \\
pollen size $(\mu \mathrm{m})$ & $47.8 \pm 1.8$ & $47.7 \pm 1.9$ & $47.7 \pm 1.6$ \\
\hline
\end{tabular}

Data are expressed as the mean \pm standard deviation of these mesurements.

Table 3. Summary of the crossing experiment with Rosa Xhybrida cultivars

\begin{tabular}{|c|c|c|c|c|c|c|c|c|c|c|}
\hline & \multicolumn{2}{|c|}{ WKS82 } & \multicolumn{4}{|c|}{ WKS82/130-4-1 } & \multicolumn{4}{|c|}{ WKS82/130-9-1 } \\
\hline & $\begin{array}{l}\text { crossed } \\
\text { number }\end{array}$ & $\begin{array}{l}\text { fruit set } \\
\text { rate }(\%)\end{array}$ & $\begin{array}{l}\text { crossed } \\
\text { number }\end{array}$ & $\begin{array}{l}\text { fruit set } \\
\text { rate }(\%)\end{array}$ & $\begin{array}{l}\text { analyzed } \\
\text { seed } \\
\text { number }\end{array}$ & $\begin{array}{l}\text { transgene } \\
\text { detected } \\
\text { rate }(\%)\end{array}$ & $\begin{array}{l}\text { crossed } \\
\text { number }\end{array}$ & $\begin{array}{l}\text { fruit set } \\
\text { rate }(\%)\end{array}$ & $\begin{array}{l}\text { analyzed } \\
\text { seed } \\
\text { number }\end{array}$ & $\begin{array}{l}\text { transgene } \\
\text { detected } \\
\text { rate }(\%)\end{array}$ \\
\hline \multicolumn{11}{|c|}{ special netted greenhouse trial } \\
\hline Queen Elizabeth & 20 & 95.0 & 20 & 95.0 & 94 & 0.0 & 20 & 100.0 & 94 & 0.0 \\
\hline Gold Bunny & 20 & 80.0 & 20 & 70.0 & 94 & 0.0 & 20 & 70.0 & 94 & 0.0 \\
\hline \multicolumn{11}{|l|}{ field trail } \\
\hline Queen Elizabeth & 41 & 65.8 & 41 & 56.1 & 38 & 0.0 & 42 & 45.2 & 37 & 0.0 \\
\hline Gold Bunny & 64 & 21.8 & 60 & 25.0 & 63 & 0.0 & 60 & 25.0 & 46 & 0.0 \\
\hline
\end{tabular}

time, flower diameter, number of petals, number of anthers, length of anthers, and width of anthers were measured in a contained or special-netted greenhouse. The same parameters were measured again during a field trial in September and October 2006.

In Australia, plant height and stem length was measured in a similar comparative trial but in this case plants were grown in a commercial hydroponic system. Flower morphology characters were also measured. Plants were grown from July 2006 until February 2007, at which time flower and plant morphology data was collected.

\section{Comparison of temperature tolerance}

Cold-tolerance and heat-tolerance at the early stage of growth of the host and the two GM rose lines were assessed by growing plants in a climate chamber (NK System BIOTRON NC350, Nippon Ika Co., Tokyo, Japan) maintained at high temperature $\left(35^{\circ} \mathrm{C}\right)$ or low temperature $\left(5^{\circ} \mathrm{C}\right)$ for one month. In field trials these plants were also grown outside in winters of 2006 and 2007 and in the summer of 2006.

\section{Cross-compatibility}

a) Pollen production and viability

In June 2005 and June 2006, pollen was collected from flowers of the host and the two GM rose lines of plants that flowered in a special-netted greenhouse, a vinyl plastic covered house and outside. Pollen morphology was observed using optical microscopes DM6000 B (LEICA, Mannheim, Germany) and BX9 (Olympus, Tokyo, Japan). The pollen was then stained with acetocarmine solution to estimate pollen viability. The number of stained pollen grains was counted under a stereomicroscope MZFL III (LEICA). Pollen was germinated on boric-acid media plates $(10 \%$ sucrose, $50 \mathrm{ppm}$ boric acid and $1 \%$ agar) at $25^{\circ} \mathrm{C}$ for $2 \mathrm{~h}$ to further estimate viability.

\section{b) Pollen dispersal}

Flowers showing stigmas protruding and pollen on the anthers were placed in front of a fan (Shinkansen FHC-2100, Fukusui Ltd., Osaka) in a contained greenhouse. The distance between the flowers and the fan was $50 \mathrm{~cm}$ and the wind speed was $4 \mathrm{~m}$ $\mathrm{s}^{-1}$. Microscope slides coated with vaseline were placed horizontally behind the flower at $10 \mathrm{~cm}$ intervals from $10 \mathrm{~cm}$ to $150 \mathrm{~cm}$. After $15 \mathrm{~h}$, the number of trapped pollen grains on the vaseline-covered slides was counted using the stereomicroscope.

\section{c) Artificial crossing with cultivated rose and wild rose} species

The host and the two GM rose lines were artificially crossed to R. multiflora in April 2005 and with Rosa $\times$ hybrida varieties Queen Elizabeth and Gold Bunny and wild species $R$. multiflora, $R$. luciae and $R$. rugosa in May 2005. Pollen collected from dehiscent anthers was placed on stigmas of de-anthered recipient plants using a small brush, and each flower was covered with a paper bag. After 2 months, seeds 


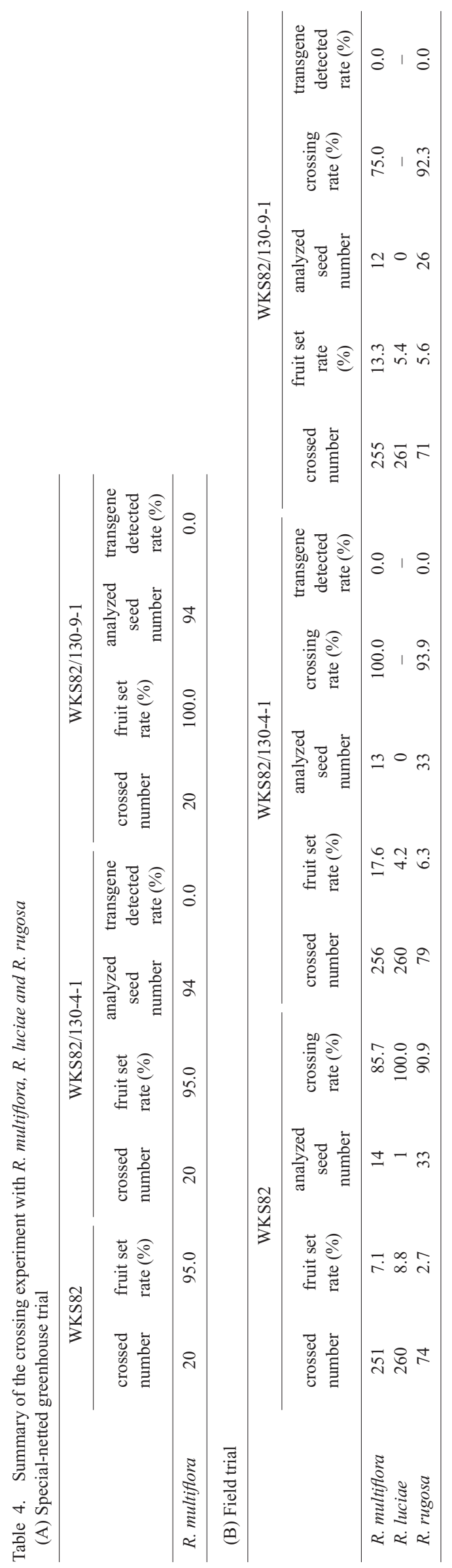

were collected and after a further 3 months at $4^{\circ} \mathrm{C}$, were sown in soil. Genomic DNA was extracted from the seedlings for analysis. The seeds that did not germinate were recovered from the soil and the DNA of the embryo was extracted and amplified using REPLI-g Midi Kit (QIAGEN) for PCR analysis.

\section{d) Simulation of crossing by insect vectors}

About fifty bees (Bombus ignites, Arysta LifeScience Co., Kobe, Japan) were released into a net container $(1.5 \mathrm{~m} \times 1.5 \mathrm{~m}$ $\times 1.5 \mathrm{~m}$ ) that contained flowering $R$. multiflora, flowering host plants and flowering plants of the two GM rose lines. After 24 $\mathrm{hr}$, the $R$. multiflora plant was removed and their seeds allowed to set for molecular analysis of the embryos.

\section{e) Natural crossing in the field}

In June 2006, flowering $R$. multiflora plants, each having about 500 flowers, were placed at distances of $1 \mathrm{~m}$ and $5 \mathrm{~m}$ from the flowering host and flowering plants of the two GM rose lines. Plants were left to naturally pollinate for 23 days. The fruits were collected from the $R$. multiflora plants after 3 months and their seeds were harvested for analysis.

\section{f) Crossing with R. acicularis}

Pollen of the host was crossed on site with de-anthered $R$. acicularis plants that were growing outside at the three sites in Hokkaido.

\section{Production of allelopathic substances in GM roses}

a) Used soil

The host and the two GM rose lines were cultivated for 6 months in a special-netted greenhouse (from October 2004 to April 2005), the vinyl plastic covered house (from May 2006 to November 2006) and outside (from May 2006 to November 2006). Used soil was extracted from around the plants and 125 lettuce seeds were sown in this used soil. After two weeks germination and growth of the lettuce seedlings were measured.

\section{b) Residual plant material}

After cultivation of the host and the two GM rose lines in the special-netted greenhouse (from October 2004 to April 2005), the vinyl plastic covered house (from May 2006 to November 2006) and the outside (from May 2006 to November 2006), the plants were ploughed into the soil. 125 lettuce seeds were sown in the plant/soil mix and cultivated in a contained greenhouse or vinyl plastic covered house for two weeks. After this time, germination and growth of the lettuce seedlings was measured.

\section{Soil microorganism profile}

Soil in which the host and the two GM rose lines were grown was collected. Thirty grams of dried soil was suspended in 270 $\mathrm{ml}$ of sterilized saline in a glass flask. The suspension was then diluted from $10^{1}$ to $10^{4}$ with sterilized saline. For detection of bacteria, fungi and actinomycetes, $0.1 \mathrm{ml}$ of suspension of each dilution were spread on three different agar medium. TSA medium containing $30 \mathrm{gl}^{-1}$ tryptic soy broth (Becton, Dickinson and Company, Franklin Lakes, USA), $15 \mathrm{gl}^{-1}$ bacto agar (Becton, Dickinson and Company) and $0.1 \mathrm{gl}^{-1}$ 
Table 5. Summary of the bee-mediated crossing experiment with $R$. multiflora

\begin{tabular}{|c|c|c|c|c|c|c|c|c|c|c|}
\hline & \multicolumn{2}{|c|}{ WKS 82} & \multicolumn{4}{|c|}{ WKS82/130-4-1 } & \multicolumn{4}{|c|}{ WKS82/130-9-1 } \\
\hline & $\begin{array}{l}\text { crossed } \\
\text { number }\end{array}$ & $\begin{array}{l}\text { fruit set } \\
\text { rate }(\%)\end{array}$ & $\begin{array}{l}\text { crossed } \\
\text { number }\end{array}$ & $\begin{array}{l}\text { fruit set } \\
\text { rate }(\%)\end{array}$ & $\begin{array}{c}\text { analyzed } \\
\text { seed } \\
\text { number }\end{array}$ & $\begin{array}{l}\text { transgene } \\
\text { detected } \\
\text { rate }(\%)\end{array}$ & $\begin{array}{l}\text { crossed } \\
\text { number }\end{array}$ & $\begin{array}{l}\text { fruit set } \\
\text { rate }(\%)\end{array}$ & $\begin{array}{c}\text { analyzed } \\
\text { seed } \\
\text { number }\end{array}$ & $\begin{array}{l}\text { transgene } \\
\text { detected } \\
\text { rate }(\%)\end{array}$ \\
\hline R. multiflora & 350 & 2.6 & 141 & 9.9 & 25 & 0.0 & 167 & 4.8 & 8 & 0.0 \\
\hline
\end{tabular}

cycloheximide (Sigma-Aldrich Co., St. Louis, USA) was used for bacteria. PDA medium containing $39 \mathrm{~g}^{-1}$ potato dextrose agar (Nissui Pharmaceutical Co., LTD., Tokyo, Japan), $0.1 \mathrm{~g}^{-1}$ rose bengal (Nacalai Tesque, Kyoto, Japan) and $0.17 \mathrm{gl}^{-1}$ chloramphenicol (Nacalai Tesque) was used for fungi and YS medium containing $2 \mathrm{gl}^{-1}$ bacto yeast extract (Becton, Dickinson and Company), $10 \mathrm{gl}^{-1}$ soluble starch (Nacalai Tesque), $15 \mathrm{gl}^{-1}$ bacto agar (Becton, Dickinson and Company), $0.25 \mathrm{gl}^{-1}$ cycloheximide (Sigma-Aldrich Corporation) and $0.04 \mathrm{gl}^{-1}$ nalidixic acid (Nacalai Tesque) was used for actinomyces. Plates were incubated at 28 or $25{ }^{\circ} \mathrm{C}$ for 3 days for bacteria and fungi respectively and $30^{\circ} \mathrm{C}$ for 6 days for actinomycetes. After incubation the number of colonies on the plate was counted as previously described (Tabei et al. 1994)

\section{Residual Agrobacterium}

Ten grams of the host and ten grams of each of the two GMrose lines were homogenized in liquid nitrogen. $20 \mathrm{ml}$ of sterilized water was added, and the homogenate was left to stand at room temperature for $2 \mathrm{~h}$. The homogenized solutions were spread on YEB medium $\left(5 \mathrm{gl}^{-1}\right.$ bacto yeast extract (Becton, Dickinson and Company), $1 \mathrm{gl}^{-1}$ peptone (Becton, Dickinson and Company), $1 \mathrm{gl}^{-1}$ sucrose (Nacalai Tesque), $0.5 \mathrm{gl}^{-1}$ magnesium sulfate (Nacalai Tesque), $5 \mathrm{gl}^{-1}$ beef extract (Becton, Dickinson and Company) ) containing $20 \mathrm{mgl}^{-1}$ tetracycline and $20 \mathrm{mg}^{-1}$ rifampicin. The plates were cultured at $28^{\circ} \mathrm{C}$. After 3 days, the number of colonies was counted.

\section{Flavonoid analysis}

Flavonoids were extracted from petals, leaves and roots of the host and the two GM rose lines and their aglycones were analyzed as reported previously (Katsumoto et al. 2007).

\section{Results and discussion}

\section{Molecular analysis}

The results of the Southern analysis of the two GM rose lines using probes for the viola $F 3^{\prime} 5^{\prime} H$, torenia $5 A T$ and npt II are shown in Figure 1. In both transgenic lines there were two to four bands, indicating the T-DNA was integrated at multiple, possibly four, loci in the rose genome. PCR analyses of various organs revealed that the petals, leaves and stems of both GM rose lines contained transgenes of viola $F 3^{\prime} 5^{\prime} H$, torenia $5 A T$ and $E$. coli $n p t$ II but that the pollen and roots did not contain these transgenes (Figure 2). The petals, leaves and stems of the GM roses had transcripts of the viola $F 3^{\prime} 5^{\prime} H$ and torenia $5 A T$ at their expected sizes (1.8 kb for both) (Figure 3).
Table 6. Summary of the natural crossing experiment with $R$. multiflora at the distance of $1 \mathrm{~m}$ and $5 \mathrm{~m}$

\begin{tabular}{llrr}
\hline pollen donor & & $1 \mathrm{~m}$ & $5 \mathrm{~m}$ \\
\hline \multirow{2}{*}{ WSK82 } & total flower number & 466 & 484 \\
& total fruit set number & 206 & 145 \\
& total seed number & 1011 & 751 \\
& crossing rate (\%) & 0.0 & 0.0 \\
\hline & total flower number & 485 & 485 \\
WKS82/130-4-1 & total fruit set number & 117 & 40 \\
& total seed number & 648 & 199 \\
& crossing rate (\%) & 0.0 & 0.0 \\
& transgene detected rate (\%) & 0.0 & 0.0 \\
\hline & total flower number & 484 & 485 \\
& total fruit set number & 205 & 120 \\
WKS82/130-9-1 & total seed number & 1067 & 592 \\
& crossing rate (\%) & 0.0 & 0.0 \\
& transgene detected rate (\%) & 0.0 & 0.0 \\
\hline
\end{tabular}

\section{In situ hybridization}

The results of in situ hybridization analysis of petals from the two GM rose lines are shown in Figure 4. The transcripts of the viola $F 3^{\prime} 5^{\prime} H$ gene were detected only in the L1 layer of epidermal cells of the petals using its antisense probe. We conclude that the GM roses used in this study only carry the transgenes in the L1 layer cells and are genetic chimeras. It was reported that among rolC transgenic tobacco plants regenerated from leaf disks $6.5 \%$ are periclinal chimeras (Schmülling and Schell, 1993). The results we obtained here indicate that chimeric transgenic plants could be often generated.

\section{Growth characters and flower morphology}

The results of plant growth and morphological measurements obtained in the greenhouse and field trials in Japan are summarized in Supplemental Figure 1 and Table 1, respectively. There were no significant growth differences between the host and the two GM rose lines. The two GM rose lines had significantly less petals than the host (Table 1, Student $t$ test, level of significance $5 \%$ ). Similar results were obtained in the Australia trial (Figure 5A, Table 1). This difference is unlikely to confer an increase in the potential for the two GM rose lines to survive in the environment.

\section{Effect of temperature on growth}

No difference was observed in the growth rate of the host and the two GM rose lines when they were grown in a climate chamber (Supplemental Figure 2). All the plants examined survived over the winter and the summer in the 
Table 7. Summary of the artificial crossing experiment with $R$. acicularis

\begin{tabular}{|c|c|c|c|c|c|c|}
\hline \multirow{2}{*}{ location } & \multicolumn{2}{|c|}{ Sapporo (botanical garden) } & \multicolumn{2}{|c|}{ Sapporo (private property) } & \multicolumn{2}{|c|}{ Bibai } \\
\hline & crossed number & fruit set rate $(\%)$ & crossed number & fruit set rate $(\%)$ & crossed number & fruit set rate $(\%)$ \\
\hline R. acicularis & 90 & 1.1 & 28 & 0.0 & 87 & 0.0 \\
\hline
\end{tabular}

outside and no growth difference was observed (Supplemental Figure 3). The two GM rose lines therefore do not have an enhanced ability to survive in the environment.

\section{Characterization of pollen}

No statistically significant difference in pollen size (Student $t$ test, level of significance 5\%) was observed between the host and the two GM rose lines (Table 2), and no difference was observed in the shape of pollen. There was no statistically significant difference in the percentage of mature pollen or the rate of pollen germination (data not shown). In the artificial wind experiment neither the pollen of the host nor the two GM rose lines was dispersed to any of the capture slides. These results indicate that the two GM rose lines do not have an increased fecundity as a result of increased pollen viability to mobility.

\section{Artificial hybridization with Rosa $\times$ hybrida}

Pollen of the host and the two GM rose lines was used to successfully fertilize cv. Queen Elizabeth and Gold Bunny in a special-netted greenhouse at similar high efficiency (Table 3). A total of 560 seeds were obtained and about 100 from each variety were analyzed by PCR. None of the seed carried the transgenes. The results are consistent with the observation that the two GM rose lines carry the transgene only in L1 layer cells as this cell layer does not contribute to the formation of pollen cells.

\section{Artificial crossing with $R$. multiflora, R.luciae and $R$. rugosa}

Artificial crossing of pollen of the host and the two GM rose lines with $R$. multiflora yielded fruits and seeds at low frequency and the transgene was not detected in the progeny (Table 4A). The crossing experiment was carried out several times in the field with the results shown in Table 4B. Fruits and seeds were obtained at low frequency. Most of the resultant seeds were hybrids between $R$. multiflora and Rosa $\times$ hybrida because the $K S N$ locus was detected (data not shown), and the rest were selfed seeds of $R$. multiflora. None of the assessed seeds contained the transgene.

\section{Natural crossing}

Only 33 seeds were obtained by the bee pollination experiment and these seeds did not carry the transgenes (Figure 5B, Table 5). The seeds collected from $R$. multiflora in the field trial did not contain either the KSN
Table 8. Summary of alleopathy assay of soils derived from the host and the two GM rose lines

(A) Used soil

\begin{tabular}{lcc}
\hline \multicolumn{1}{l}{ line } & $\begin{array}{c}\text { germination rate } \\
(\%)\end{array}$ & $\begin{array}{c}\text { average of fresh weight } \\
(\mathrm{mg})\end{array}$ \\
\hline \hline \multicolumn{3}{l}{ special netted greenhouse trial } \\
\hline WKS82 & $94.4 \pm 5.4$ & $89.3 \pm 6.5$ \\
WKS82/130-4-1 & $96.8 \pm 3.3$ & $93.3 \pm 22.9$ \\
WKS82/130-9-1 & $95.2 \pm 3.3$ & $95.3 \pm 11.8$ \\
\hline field trial (vinyl plastic covered house) \\
\hline WKS82 & $96.0 \pm 4.4$ \\
WKS82/130-4-1 & $91.2 \pm 4.7$ & $100.0 \pm 6.2$ \\
WKS82/130-9-1 & $95.2 \pm 5.9$ & $99.6 \pm 6.2$ \\
\hline field trail (outside) & \\
\hline WKS82 & $92.8 \pm 8.9$ & $88.3 \pm 8.2$ \\
WKS82/130-4-1 & $98.4 \pm 3.2$ & $91.6 \pm 10.6$ \\
WKS82/130-9-1 & $98.4 \pm 2.0$ & $88.5 \pm 5.8$ \\
\hline
\end{tabular}

(B) Soil containing residual plant material

\begin{tabular}{lrc}
\hline \multicolumn{1}{l}{ line } & $\begin{array}{c}\text { germination rate } \\
(\%)\end{array}$ & $\begin{array}{c}\text { average of fresh weight } \\
(\mathrm{mg})\end{array}$ \\
\hline \hline \multicolumn{3}{l}{ special netted greenhouse trial } \\
\hline WKS82 & $96.8 \pm 3.3$ & $51.2 \pm 5.7$ \\
WKS82/130-4-1 & $100.0 \pm 0.0$ & $53.8 \pm 7.1$ \\
WKS82/130-9-1 & $98.4 \pm 3.6$ & $51.6 \pm 4.0$ \\
\hline field trial (vinyl plastic covered house) \\
\hline WKS82 & $92.0 \pm 5.7$ \\
WKS82/130-4-1 & $96.0 \pm 4.4$ & $61.5 \pm 3.9$ \\
WKS82/130-9-1 & $93.6 \pm 4.1$ & $63.1 \pm 5.4$ \\
\hline field trail (outside) & \\
\hline WKS82 & $96.0 \pm 3.6$ & $70.9 \pm 4.4$ \\
WKS82/130-4-1 & $94.4 \pm 7.8$ & $72.5 \pm 3.1$ \\
WKS82/130-9-1 & $96.0 \pm 4.4$ & $67.2 \pm 3.2$ \\
\hline
\end{tabular}

Germination rate and fresh weight were measured two weeks after sowing 125 lettuce seeds. Data are expressed as the mean \pm standard deviation of these mesurements.

gene or transgenes (Table 6). These results indicate that gene dispersal from the host and the two GM rose lines to $R$. multiflora, if any, is likely to be rare under natural condition. We previously showed that gene transfer from Rosa $\times$ hybrida to Japanese wild roses could not be detected (Nakamura et al. 2011). As the two GM rose lines used in this study are transgenic only in L1 cells, transgene flow from these GM rose lines to Japanese wild roses could not occur.

Crossing with $R$. acicularis

The results of crossing with $R$. acicularis, the only 
Table 9. Soil microorganism profile

\begin{tabular}{lccc}
\hline line organism & $\begin{array}{c}\text { bacteria } \\
\left(\times 10^{6}\right)\end{array}$ & $\begin{array}{c}\text { fungi } \\
\left(\times 10^{4}\right)\end{array}$ & $\begin{array}{c}\text { actinomycetes } \\
\left(\times 10^{4}\right)\end{array}$ \\
\hline \hline \multicolumn{4}{l}{ special netted greenhouse trial } \\
\hline WKS82 & $5.81 \pm 1.46$ & $1.95 \pm 0.11$ & $2.97 \pm 1.46$ \\
WKS82/130-4-1 & $4.94 \pm 1.74$ & $1.85 \pm 0.33$ & $2.60 \pm 0.74$ \\
WKS82/130-9-1 & $5.39 \pm 1.79$ & $1.68 \pm 0.49$ & $3.28 \pm 0.78$ \\
\hline field trial (vinyl plastic covered house) & & \\
\hline WKS82 & $1.27 \pm 0.22$ & $1.45 \pm 0.15$ & $2.97 \pm 0.47$ \\
WKS82/130-4-1 & $1.15 \pm 0.21$ & $1.50 \pm 0.28$ & $2.94 \pm 0.25$ \\
WKS82/130-9-1 & $1.17 \pm 0.25$ & $1.36 \pm 0.30$ & $2.84 \pm 0.35$ \\
\hline field trail (outside) & & & \\
\hline WKS82 & $1.34 \pm 0.27$ & $2.24 \pm 0.27$ & $0.94 \pm 0.17$ \\
WKS82/130-4-1 & $1.11 \pm 0.36$ & $2.18 \pm 0.26$ & $1.01 \pm 0.17$ \\
WKS82/130-9-1 & $1.16 \pm 0.33$ & $2.50 \pm 0.18$ & $0.98 \pm 0.26$ \\
\hline
\end{tabular}

Data are expressed as the mean \pm standard deviation $\left(\mathrm{cfu} \mathrm{g}^{-1}\right.$ dried soil weight) of 5 plates.

tetraploid wild rose in Japan, are summarized in Table 7. Crossing in Hokkaido only gave one fruit and its seeds didn't germinate and rotted in soil. Crossing in Osaka did not result in mature fruits.

\section{Allelopathy studies}

The germination rate of lettuce seeds and the growth of seedlings is summarized in Table 8. There was no significant difference between the host and the two GM rose lines in either experiment. No statistically significant difference was observed in the number of bacteria, filamentous fungi, and actinomycetes around the environment of the host and the two GM rose lines (Table 9). These results indicate that there is no production of novel toxic compounds in the two GM rose lines. We have previously reported that the fragrance and the volatile compounds of the host and the two GM rose lines are not significantly different (Nakamura et al. 2010).

\section{Residual Agrobacterium}

No residual Agrobacterium was detected in any sample from the two GM rose lines. Agrobacterium containing the heterologous genes used to generate the two GM rose lines have no effect on the environment (data not shown).

\section{Flavonoid analysis}

Anthocyanidins and aglycones derived from petals, leaves and roots were measured (Table 10). Only the two GM rose lines contained delphinidin and myricetin. These compounds are produced by the action of the viola $F 3^{\prime} 5^{\prime} H$. We previously reported that the GM roses contain the anthocyanins delphidinin 3, 5-diglucoside, delphidinin 3-glucoside and 5-(aromatic acyl) glucoside (Katsumoto et al. 2007).
Table 10. Anthocyanidin and flavonol content of various organs (A) Anthocyanidins

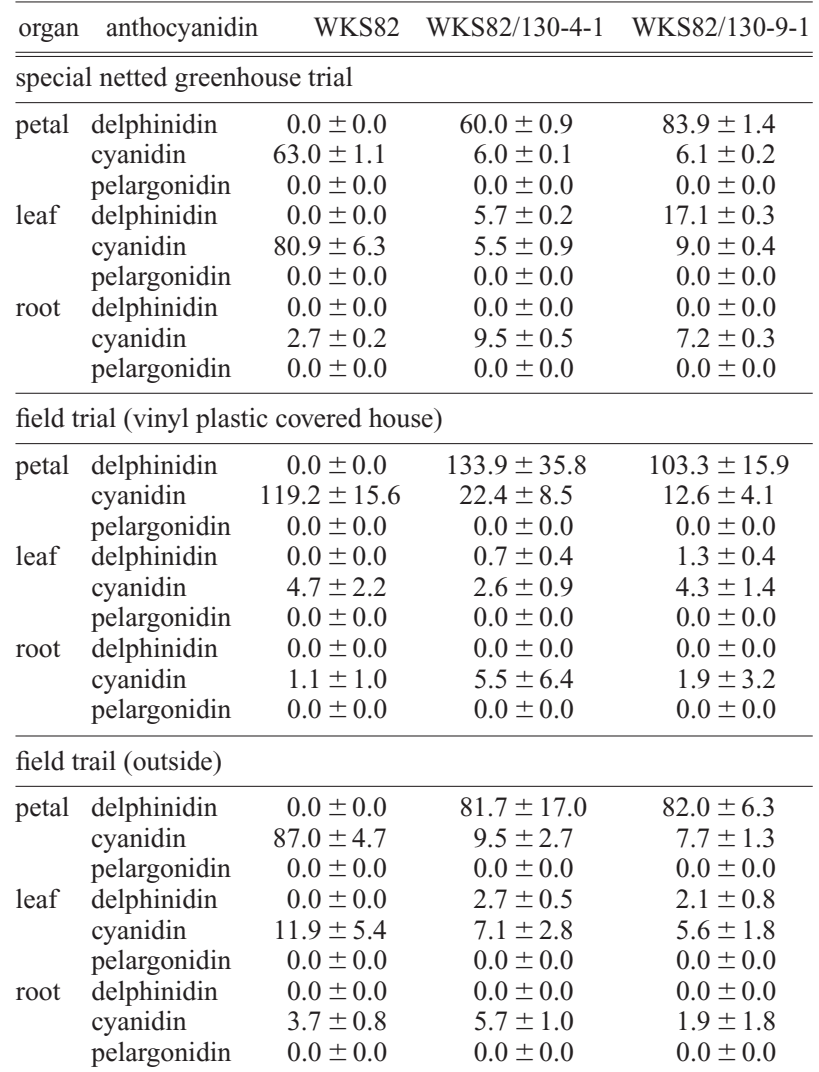

(B) Flavonols

\begin{tabular}{|c|c|c|c|c|}
\hline \multicolumn{3}{|c|}{ organ anthocyanidin WKS82 } & WKS82/130-4-1 & WKS82/130-9-1 \\
\hline \multicolumn{5}{|c|}{ special netted greenhouse trial } \\
\hline \multirow[t]{3}{*}{ petal } & myricetin & 0.0 & 920.0 & 1751.0 \\
\hline & quercetin & 2791.0 & 157.0 & 310.0 \\
\hline & kaempferol & 95.0 & 4.0 & 17.0 \\
\hline \multirow[t]{3}{*}{ leaf } & myricetin & $0.0 \pm 0.0$ & $387.0 \pm 5.9$ & $380.0 \pm 6.6$ \\
\hline & quercetin & $768.0 \pm 14.8$ & $122.0 \pm 0.6$ & $99.0 \pm 2.0$ \\
\hline & kaempferol & $39.0 \pm 0.9$ & $0.0 \pm 0.0$ & $0.0 \pm 0.0$ \\
\hline \multirow[t]{3}{*}{ root } & myricetin & $0.0 \pm 0.0$ & $0.0 \pm 0.0$ & $0.0 \pm 0.0$ \\
\hline & quercetin & $0.0 \pm 0.0$ & $0.0 \pm 0.0$ & $0.0 \pm 0.0$ \\
\hline & kaempferol & $0.0 \pm 0.0$ & $0.0 \pm 0.0$ & $0.0 \pm 0.0$ \\
\hline \multicolumn{5}{|c|}{ field trial (vinyl plastic covered house) } \\
\hline \multirow[t]{3}{*}{ petal } & myricetin & $0.0 \pm 0.0$ & $1591.4 \pm 246.0$ & $1324.4 \pm 125.0$ \\
\hline & quercetin & $2472.2 \pm 334.9$ & $427.5 \pm 224.5$ & $253.9 \pm 48.7$ \\
\hline & kaempferol & $84.5 \pm 15.8$ & $13.0 \pm 9.3$ & $6.4 \pm 1.3$ \\
\hline \multirow[t]{3}{*}{ leaf } & myricetin & $0.0 \pm 0.0$ & $719.9 \pm 47.4$ & $735.9 \pm 89.3$ \\
\hline & quercetin & $1415.9 \pm 241.8$ & $732.6 \pm 41.8$ & $1036.8 \pm 130.8$ \\
\hline & kaempferol & $57.1 \pm 19.0$ & $47.4 \pm 5.5$ & $65.9 \pm 10.6$ \\
\hline \multirow[t]{3}{*}{ root } & myricetin & $0.0 \pm 0.0$ & $0.0 \pm 0.0$ & $0.0 \pm 0.0$ \\
\hline & quercetin & $0.0 \pm 0.0$ & $0.0 \pm 0.0$ & $0.0 \pm 0.0$ \\
\hline & kaempferol & $0.0 \pm 0.0$ & $0.0 \pm 0.0$ & $0.0 \pm 0.0$ \\
\hline \multicolumn{5}{|c|}{ field trail (outside) } \\
\hline \multirow[t]{3}{*}{ petal } & myricetin & $0.0 \pm 0.0$ & $1359.3 \pm 373.5$ & $1500.6 \pm 165.9$ \\
\hline & quercetin & $2335.3 \pm 102.4$ & $268.1 \pm 80.9$ & $268.2 \pm 48.9$ \\
\hline & kaempferol & $58.6 \pm 4.7$ & $0.0 \pm 0.0$ & $0.0 \pm 0.0$ \\
\hline \multirow[t]{3}{*}{ leaf } & myricetin & $0.0 \pm 0.0$ & $1513.6 \pm 100.5$ & $582.8 \pm 60.4$ \\
\hline & quercetin & $2652.5 \pm 1078.8$ & $3631.0 \pm 6.9$ & $2355.3 \pm 214.0$ \\
\hline & kaempferol & $83.1 \pm 36.3$ & $105.9 \pm 5.6$ & $97.8 \pm 23.7$ \\
\hline \multirow[t]{3}{*}{ root } & myricetin & $0.0 \pm 0.0$ & $0.0 \pm 0.0$ & $0.0 \pm 0.0$ \\
\hline & quercetin & $0.0 \pm 0.0$ & $0.0 \pm 0.0$ & $0.0 \pm 0.0$ \\
\hline & kaempferol & $0.0 \pm 0.0$ & $0.0 \pm 0.0$ & $0.0 \pm 0.0$ \\
\hline
\end{tabular}

Data are expressed as the mean \pm standard deviation $\left(\mu \mathrm{gg}^{-1}\right.$ fresh weight) of three plants. 


\section{Conclusion}

Roses have been utilized for fragrance, medicine and herbal remedies for hundreds of years and can be regarded as a safe plant species for human use. Cultivated roses are not a weedy species. The data obtained here show that the release of the two GM rose lines is unlikely to have an affect on biodiversity in Japan and on the basis of the data shown here, general release permission was granted for the two GM rose lines in January 31, 2008. One of the two GM rose lines (WKS82/130-4-1) was launched commercially in November 2009 in Japan. As gene flow from RosaX hybrida to Japanese wild roses is very rare, if possible at all (this study, Nakamura et al. 2011). We believe assessment of transgenic roses in future may be relaxed.

In Japan, considerable efforts have been made to produce novel floricultural crops using genetic engineering. For example, colour modified petunia, torenia and gentian (reviewed by Nishihara and Nakatuska 2010 and morphologically modified torenia (Narumi et al. 2008), cyclamen (Tanaka et al. 2011), gentian (Nakatsuka et al. 2011), morning glory (Ono et al. 2011; Sage-Ono et al. 2011) and rose (Gion et al. 2011) have been developed. Insect resistant chrysanthemum (Shinoyama et al. 2008) has also been reported. None of these potential products have been grown in field trials although this is essential to evaluate the performance of GM floricultural crops (Tanaka et al. 2010). The regulatory system on GM plants in Japan should be improved so that field trials can be carried out more readily for environmentally benign plant species, such as rose.

\section{Acknowledgements}

The authors are grateful to Bio-oriented Technology Research Advancement Institution for giving us an opportunity to write this paper. We thank Dr. Hikaru Iwata (Wakunaga Pharmaceutical Co., Ltd.) for his generous and valuable advice about $K S N$ locus analysis. Crossing with $R$. acicularis was supported by Dr. Takayuki Azuma (Botanical Garden, Hokkaido University), Mr. Takao Sato, Youichi Wakita (Hokkaido Forestry Research Institute) and Mses. Atsuko Yamazaki. Technical advice and information of rose was supported by Prof. Yoshihiro Ueda (Gifu International Academy of Holticulture), Prof. Shogo Matsumoto (Nagoya University), Dr. Yuki Mikanagi (Natural History Museum and institute, Chiba) and Dr. Shunsuke Takeuchi (Keisei Rose Nursery). The authors thank Mses. Kitai, Murakami, Takagi, Akagi, Takeuchi, Nakata, Takemura, Nakamura, Kobayashi and Egami for technical assistance.

\section{References}

Aida M, Ishida Y, Tasaka M (1999) Shoot meristem and cotyledon formation during Arabidopsis embryogenesis: interaction among the CUP-SHAPED COTYLEDON and SHOOT MERISTEMLESS genes. Develpoment 126: 1563-1570

Fukuchi-Mizutani M, Okuhara H, Fukui Y, Nakao M, Katsumoto
Y, Yonekura-Sakakibra K, Kusumi T, Hase T, Tanaka Y (2003) Biochemical and molecular characterization of a novel UDPglucose: anthocyanin 3 '-O-glucosyltransferase, a key enzyme for blue anthocyanin biosynthesis, from gentian. Plant Physiol 132: $1652-1663$

Gion K, Suzuri R, Shikata M, Mitsuda N, Oshima Y, Koyama T, Ohme-Takagi M, Ohtsubo N, Tanaka Y (2011) Morphological changes of Rosa $\times$ hybrida by a chimeric repressor of Arabidopsis TCP3. Plant Biotechnol 28: 149-152

Gudin S (2000) Rose: Genetics and breeding. In: Janick J (ed) Plant Breeding Reviews, vol 17 John Wiley \& Sons, Hoboken, pp 159-189

Katsumoto Y, Mizutani M, Fukui Y, Brugliera F, Holton T, Karan M, Nakamura N, Yonekura-Sakakibara K, Togami J, Pigeaire A et al. (2007) Engineering of the rose flavonoid biosynthetic pathway successfully generated blue-hued flowers accumulating delphinidin. Plant Cell Physiol 48: 1589-1600

Nakamura N, Joichi A, Terashima Y, Tanaka Y (2010) Dream comes true: development of a blue rose "Applause" and its fragrance. J Jpn Assoc Odor Environ 41: 150-156

Nakamura N, Tems U, Fukuchi-Mizutani M, Chandler S, Matsuda Y, Takeuchi S, Matsumoto S, Tanaka Y (2011) Molecular based evidence for a lack of gene-flow between Rosa $\times$ hybrida and wild Rosa species in Japan. Plant Biotechnol 28: 245-250

Nakatsuka T, Saito M, Yamada E, Nishihara M (2011) Production of picotee-type flowers in Japanese gentian by CRES-T. Plant Biotechnol 28: 173-180

Narumi T, Aida R, Niki T, Nishijima T, Mitsuda N, Hiratsu K, Ohme-Takagi M, Ohtsubo N (2008) Chimeric AGAMOUS repressor induces serrated petal phenotype in Torenia fournieri similar to that induced by cytokinin application. Plant Biotechnol 25: 45-53

Nishihara M, Nakatsuka T (2010) Genetic engineering of novel flower colors in floricultural plants: Recent advances via transgenic approaches. In Jain SM, Ochatt SJ (eds) Protocols for in vitro propagation of ornamental plants. Humana Press, Totowa, pp 325-347

Sage-Ono K, Ozeki Y, Hiyama S, Higuchi Y, Kamada H, Mitsuda N, Ohme-Takagi M, Ono M (2011) Induction of double flowers in pharbitisnil using a class-C MADS-box transcription facter with Chimeric REpressor gene-Silencing Technology. Plant Biotechnol 28: 153-165

Schmülling T, Schell J (1993) Transgenic tobacco plants regenerated from leaf disks can be periclinal chimeras. Plant Mol Biol 21: 705-708

Shinoyama H, Mochizuki A, Nomura Y, Kamada H (2008) Environmental risk assessment of genetically modified chrysanthemums containing a modified crylAb gene from Bacillus thuringiensis. Plant Biotechnol 25: 17-29

Tabei Y, Oosawa K, Nishimura S, Watanabe S, Tsuchiya K, Yoshioka K, Fujisawa I, Nakajima K (1994) Environmental risk evaluation of the transgenic melon with coat protein gene of cucumber mosaic virus in a closed and semi-closed greenhouse II. Jpn J Breed 44: 207-211

Tanaka Y, Brugliera F, Chandler S (2009) Recent progress of flower colour modification by biotechenology. Int $\mathrm{J} \mathrm{Mol} \mathrm{Sci}$ 10: $5350-5369$

Tanaka Y, Brugliera F, Lalc G, Senior M, Dyson B, Nakamura N, Katsumoto Y, Chandler S (2010) Flower colour modification by engineering the flavonoid biosynthetic pathway: practical perspectives. Biosci Biotechnol Biochem 74: 1760-1769

Tanaka Y, Yamamura T, Oshima Y, Mitsuda N, Koyama T, OhmeTakagi M, Terakawa T (2011) Creating ruffled flower petals in Cyclamen persicum by expression of the chimeric cyclamen TCP repressor. Plant Biotechnol 28: 141-147 